\title{
Molecular characterisation of varicella zoster virus genotypes in Sri Lanka
}

\author{
J Lohitharajah¹, G N Malavige ${ }^{1}$, A Wijewickrama ${ }^{3}$, A Ambagawita ${ }^{1}$, A L P Seneviratne ${ }^{2}$, G Ogg $^{4}$ \\ (Index words: varicella zoster virus, genotype, Sri Lanka, chickenpox)
}

\begin{abstract}
Introduction Genotyping of wild type of varicella zoster virus (VZV) in Sri Lanka would help to distinguish the VZV wild type infection from varicella vaccine associated infections.

Methods PCR-RFLP analysis of VZV ORF 38, 54 and 62 was used for genotyping in VZV from blood or vesicular fluid from 31 patients with chickenpox or herpes zoster. The Pstl restriction site of ORF 38, Bg/l restriction site of ORF 54 and Smal restriction site of ORF 62 were analyzed using RFLP to determine the genotype.

Results Except for one strain, all other VZV isolates had the genotype characteristic of the wild type VZV strain Pstl ${ }^{+} \mathrm{Bg} / \mathrm{l}^{+} \mathrm{Smal}^{-}$, which was characteristic of the Asian strain. None of the isolates had the American or the European VZV profile (Pstl $\left.\mathrm{Bg} / \mathrm{I}^{-}\right)$but were similar to isolates from Africa and Asia $\left(P s t l^{+} B g / l^{+}\right)$. Interestingly, one of the VZV strains isolated from a patient with chickenpox had the characteristic genotype of the vaccine strain Pstl $^{-} \mathrm{Bg}^{+} \mathrm{I}^{+} \mathrm{Smal}^{+}$.

Conclusions The genotype of the VZV in Sri Lanka is similar to the Asian VZV genotype and can be easily distinguished from the VZV vaccine strain by using the polymorphisms in ORF 38, ORF 54 and ORF 62.
\end{abstract}

\section{Ceylon Medical Journal 2013; 58: 153-6}

\section{Introduction}

Varicella zoster virus (VZV) causes chicken pox (varicella) during primary infection, which is usually a benign self-limiting illness in children. However, it can cause severe disease and even death in adults, neonates, pregnant women and in the immunosuppressed [1]. As common to all alpha herpes viruses it then becomes latent in the dorsal root sensory ganglia. The virus may reactivate later in life to cause shingles (herpes zoster) [2].

VZV is a double stranded DNA virus and only one serotype exists. The VZV genome is highly conserved with 72 ORFs [2]. The genomic variation between VZV strains is limited to about $0.05 \%$ to $0.06 \%$ and consists almost entirely of single nucleotide polymorphisms (SNPs) dispersed across the genome [3]. On the basis of analysis of SNP at least 3-4 geographically distinct genotypes have been described. By analysis of selected SNPs in ORFs 1, 21, 50 and 54, Barrett-Muir et al have identified four genotypes; namely, A (Africa/Asia), B and C (Europe and America) and J (Far East) [4]. Loparev et al have shown that by the analysis of a short region in ORF22, three major genotypes can be distinguished: E (European), J (Japanese), and M (mosaic). J strains are most common in Japan and $\mathrm{E}$ strains are most common in temperate latitudes [5]. The $\mathrm{M}$ strains were commonest in Africa, India, China and Central America [5, 6].

The epidemiology of VZV infections is remarkably different in tropical and temperate climates. In the tropics, infection mainly occurs among young adults resulting in significant morbidity, higher hospital admission rates and mortality [7]. The seroprevalance rates of VZV among 5 year olds in India was $29 \%$ while in Sri Lanka it was 10\% $[8,9]$. In Sri Lanka, only $50 \%$ of those living in the rural areas had chickenpox even at the age of 60 years [9]. Determining the genotype of wild type VZV in Sri Lanka could possibly help us to determine if the genotypic differences could contribute to differences in disease transmission. In addition, genotyping the wild type strain would also enable us to differentiate VZV infection due to the wild type virus from the vaccine associated infection.

RFLP analysis of the PCR products of VZV ORF 38 , 54 and 62 , has been used to distinguish the wild type strain for the Oka virus (VZV vaccine strain) $[6,10]$. All Japanese strains (Oka vaccine strain) are either $\mathrm{Pst}^{\mathrm{I}^{+}} \mathrm{BglI}^{+}$or PstI-BglI+ $\mathrm{I}^{+}$, while most isolates in the United States, Germany and the United Kingdom are PstI ${ }^{+} B g I^{-}[10]$. PstI ${ }^{+} B g I^{+}$strains have been shown to be prevalent in countries with low adult immunity to varicella, such as India and also among Asian immigrants in European countries [11].

\section{Methods}

Thirty one isolates were obtained from either blister fluid or blood from 28 patients with chickenpox and 3 patients with herpes zoster. Informed written consent

Departments of ${ }^{1}$ Microbiology and ${ }^{2}$ Family Medicine, University of Sri Jayawardanapura, ${ }^{3}$ Infectious Diseases Hospital, Sri Lanka and ${ }^{4}$ MRC Human Immunology Unit, Weatherall Institute of Molecular Medicine, John Radcliffe Hospital, Oxford, United Kingdom.

Correspondence: JL, e-mail: <janarthani.I@gmail.com>. Received 21 August 2013 and revised version accepted 17 October 2013. Competing interests: none declared. 
was obtained from all study participants and the study was approved by the Ethical Review Committee of the University of Sri Jayawardenapura. Viral DNA was extracted using QIAmp Blood Kit (QIAGEN) according to the manufacturer's instructions and the live attenuated varicella vaccine. PCR was performed as described in previous study, using primers for ORF 38, 54 and 62 [62].

Restriction Endonuclease digestion of PCR products were carried out with 1-3 $\mu$ l of PCR product, 1-3 $\mu$ l of Restriction Endonuclease (BglI, PstI or SmaI), $4 \mu \mathrm{l}$ of Restriction Enzyme buffer (10×, Promega) and $4 \mu \mathrm{l}$ of Acetylated Bovine Serum Albumin $(10 \mu \mathrm{g} / \mu 1)$. The final reaction volume was adjusted to $20 \mu \mathrm{l}$ with DNase/RNasefree water. Reactions were incubated at $37^{\circ} \mathrm{C}$ for $\mathrm{BglI}$ and PstI or $25^{\circ} \mathrm{C}$ for SmaI overnight. BglI and PstI digested products were separated by gel electrophoresis on $3 \%$ agarose at $80 \mathrm{~V}$ for 150 minutes and 100 minutes respectively. SmaI digested products were electrophoresed on $4 \%$ agarose gel at $80 \mathrm{~V}$ for 2.5 hours.

\section{Results}

In order to characterize the genotype of the wild type VZV strain in Sri Lanka, we analysed 31 VZV isolates from patients with chicken pox or herpes zoster by RFLP of DNA fragments of open reading frames (ORFs) 38,54 , and 62 . We found that except for one strain, all other VZV isolates from clinical samples had the genotype characteristic of the wild type VZV strain $\mathrm{Pstl}^{+} \mathrm{BglI}^{+} \mathrm{SmaI}^{-}$. None of the isolates had the American or the European VZV profile ( $\mathrm{PstI}^{+} \mathrm{BglI} \mathrm{I}^{-}$) but were similar to the virus isolates from Africa and Asia $\left(\mathrm{PstI}^{+} \mathrm{Bgl \textrm {I } ^ { + }}\right)$.

\section{Restriction fragment length polymorphism (RFLP) analysis of ORF 38}

After PCR amplification with the primers for ORF 38, a 647 bp fragment was obtained as expected. Subsequent PstI digestion of the PCR products yielded two fragments of $357 \mathrm{bp}$ and $290 \mathrm{bp}$ in all except one isolate (Figure1). In contrast, the $647 \mathrm{bp}$ fragments were obtained from one isolate and the Oka vaccine strain. These results indicate that 30 Sri Lankan VZV isolates contained the PstI site in ORF 38 and one isolate and the Oka vaccine strain were negative for the PstI site.

\section{RFLP analysis of ORF 54}

PCR amplification of DNA with primers for ORF 54 produced amplicons of $497 \mathrm{bp}$ (Figure 2). The digestion of PCR product with BglI restriction enzyme resulted in two fragments of $256 \mathrm{bp}$ and $241 \mathrm{bp}$. All of the viruses analyzed, which included 31 Sri Lanka isolates and Oka vaccine strain, were positive for the BglI site.

\section{RFLP analysis of ORF 62}

PCR amplification of DNA fragments in ORF 62 produced amplicons with a size of $268 \mathrm{bp}$. Subsequent SmaI digestion of 30 of 31 analyzed VZV DNA yielded 153, 79 and $36 \mathrm{bp}$ fragments (Figure 3 ). The PCR product of the Oka vaccine strain and one Sri Lankan isolate were cleaved in a set of 112,79 and $41 / 36 \mathrm{bp}$ fragments. These results indicate that one Sri Lankan isolate and the Oka vaccine strain contain SmaI site in ORF 62 whereas others did not have the site.

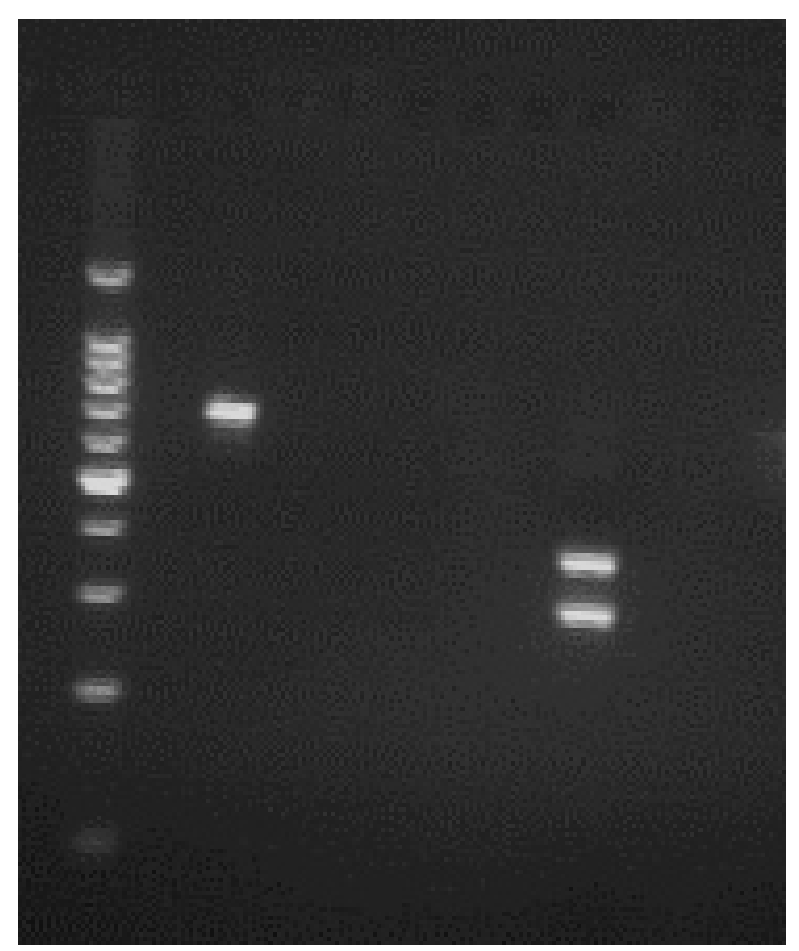

Figure 1. Pst digested and undigested DNA fragments of ORF 38 amplified products. Lane M: 100 to 1000 bp DNA ladder. Lane 2: Undigested PCR product (647 bp). Lane 9: Digested PCR products by Pst enzyme (357 bp and 290 bp).

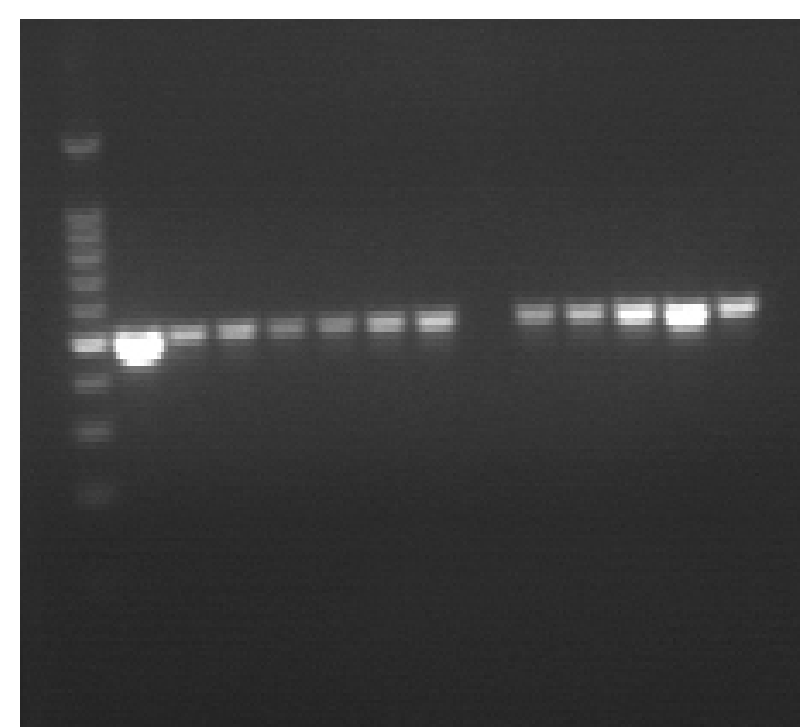

Figure 2. Amplified DNA fragments of ORF 54. Lane M: 100 to 1000 bp DNA ladder; Lane 1: PCR amplified DNA product from Oka vaccine (496 bp); Lanes 2-13: PCR amplified DNA products from blood and vesicular fluid (496 bp). 


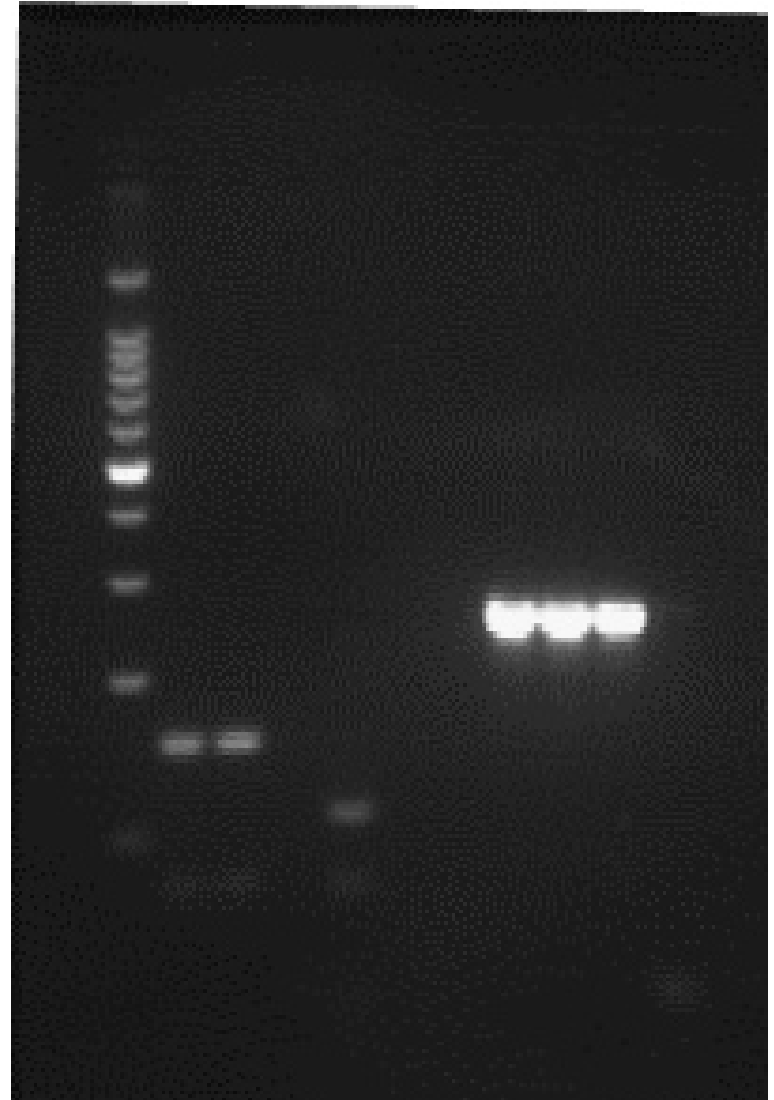

Figure 3. Sma digested and undigested DNA fragments of ORF 62 amplified products. Lane M: 100 to 1000 bp DNA ladder; Lanes 1 and 2: Digested PCR products from clinical samples (153 bp and 79 bp); Lane 4: Digested PCR products from Oka vaccine (112 bp and 79 bp); Lanes 7 9: Undigested PCR products (268 bp).

\section{Discussion}

In this study we found that the majority of the VZV strains had the genotype $\mathrm{PstI}^{+} \mathrm{BglI}^{+} \mathrm{SmaI}^{-}$, which is characteristic of the Asian/African clades [3,11]. We found that the wild type strain can be successfully differentiated from Oka strain with PCR-RFLP technique using genetic markers ORF 38, 54 and 62 . The majority of wild type VZV strains in tropical or subtropical climate are $\mathrm{PstI}^{+} \mathrm{BglI}^{+} \mathrm{SmaI}^{-}$while the dominant pattern in countries with temperate climate is $\mathrm{PstI}^{+} \mathrm{Bg} / \mathrm{I}^{-} \mathrm{SmaI} \mathrm{I}^{-}[6,10,11]$. Predominantly circulating strains in tropical countries such as Zambia, Guinea Bissau, Bangladesh, India and Singapore were $\mathrm{BgII}^{+}$marker in ORF $54[5,11]$. The circulating wild type of VZV in India was also similar to the genotype in Sri Lanka which is $\mathrm{PstI}^{+} \mathrm{BgII}^{+} \mathrm{SmaI}^{-}$[11].

Since the introduction of the live attenuated varicella zoster vaccine to Sri Lanka, the need has arisen for molecular characterisation of the wild type virus isolates in Sri Lanka, to differentiate it from the vaccine strain. Although 30/31 strains were $\mathrm{PstI}^{+} \mathrm{BgII}^{+} \mathrm{SmaI}^{-}$, one strain was $\mathrm{PstI}^{-} \mathrm{BgII}^{+} \mathrm{SmaI}$, which is characteristic of the VZV vaccine strain. The live attenuated VZV vaccine is associated with development of a rash in $5 \%$ of vaccines [12]. In addition, the vaccine virus is still able to establish latency in the vaccinated host and can be transmitted to nonimmune individuals from skin lesions of individuals with vaccine varicella resulting in primary varicella [13-16]. Therefore, the presence of the Oka virus strain in one of our patients (who was a 13 year old otherwise healthy individual) with chickenpox could have been due to transmission of the vaccine virus.

In summary we have identified that the wild type virus strain in Sri Lanka is of the $\mathrm{PstI}^{+} \mathrm{BglI}^{+} \mathrm{SmaI}^{-}$ genptype, which is characteristic of the Asian/African clades. By using RFLP of PCR products of ORF 38, 54 and 62 , we are able to differentiate the wild type virus strain from the Oka vaccine strain, which could be used to determine vaccine virus associated varicella infection.

\section{Acknowledgements}

Funding was provided by the IRQUE grant IRQUE/ CBR/RG/2009/HB/01 and the Medical Research Council, United Kingdom.

\section{References}

1. Arvin AM. Immune responses to varicella-zoster virus. Infectious Disease Clinics of North America 1996, 10: 529-70.

2. Arvin AM. Varicella-zoster virus. Clinical Microbiology Reviews 1996, 9: 361-81.

3. Quinlivan M, Breuer J. Molecular studies of Varicella zoster virus. Reviews in Medical Virology 2006; 16: 225-50.

4. Barrett-Muir W, Scott FT, Aaby P, et al. Genetic variation of varicella-zoster virus: evidence for geographical separation of strains. Journal of Medical Virology 2003; 70 Suppl 1: S42-7.

5. Loparev VN, Gonzalez A, Deleon-Carnes M, et al. Global identification of three major genotypes of varicella-zoster virus: longitudinal clustering and strategies for genotyping. Journal of Virology 2004; 78: 8349-58.

6. Liu J, Wang M, Gan L, Yang S, Chen J. Genotyping of clinical varicella-zoster virus isolates collected in China. Journal of Clinical Microbiology 2009; 47: 1418-23.

7. Malavige GN, Jones L, Kamaladasa SD, et al. Viral load, clinical disease severity and cellular immune responses in primary varicella zoster virus infection in Sri Lanka. PLoS One 2008; 3: e3789.

8. Lokeshwar MR, Agrawal A, Subbarao SD, et al. Age related seroprevalence of antibodies to varicella in India. Indian Pediatrics 2000; 37: 714-9.

9. Liyanage N, Fernando S, Malavige GN, et al. Seroprevalence of varicella zoster virus infections in Colombo District, Sri Lanka. Indian Journal of Medical Sciences 2007, 61: 128-34.

10. Sauerbrei A, Eichhorn U, Gawellek S, et al. Molecular characterisation of varicella-zoster virus strains in Germany and differentiation from the Oka vaccine strain. Journal of Medical Virology 2003, 71: 313-9. 
11. Kaushik KS, Lahiri KK, Chumber SK, et al. Molecular characterization of clinical varicella-zoster strains from India and differentiation from the oka vaccine strain. Japanese Journal of Infectious Diseases 2008; 61: 65-7.

12. Sharrar RG, LaRussa P, Galea SA, et al. The postmarketing safety profile of varicella vaccine. Vaccine 2000; 19: 916-23.

13. Quinlivan ML, Gershon AA, Al Bassam MM, et al. Natural selection for rash-forming genotypes of the varicella-zoster vaccine virus detected within immunized human hosts. Proceeding of the National Academy of Sciences of the United States of America 2007; 104: 208-12.
14. Salzman MB, Sharrar RG, Steinberg S, LaRussa P. Transmission of varicella-vaccine virus from a healthy 12 month-old child to his pregnant mother. The Journal of Pediatrics 1997; 131: 151-4.

15. Grossberg R, Harpaz R, Rubtcova E, et al. Secondary transmission of varicella vaccine virus in a chronic care facility for children. The Journal of Pediatrics 2006; 148: 842-4.

16. LaRussa P, Steinberg S, Meurice F, Gershon A. Transmission of vaccine strain varicella-zoster virus from a healthy adult with vaccine-associated rash to susceptible household contacts. The Journal of Infectious Diseases 1997; 176: $1072-5$.

\title{
Validation of the Sinhala version of the Chronic Liver Disease Questionnaire (CLDQ) for assessment of health related quality of life among Sri Lankan cirrhotics
}

\author{
C K Ranawaka ${ }^{1}$, J K N D Miththinda ${ }^{1}$, S M Senanayake ${ }^{1}$, W R S de Alwis ${ }^{2}$, M N F Mufeena ${ }^{2}$, M A \\ Niriella $^{2}$, A S Dassanayake ${ }^{3}$, A P de Silva ${ }^{2}$, A Pathmeswaran ${ }^{4}$, H J de Silva ${ }^{2}$ \\ (Index words: cirrhosis, quality of life (QOL), Chronic Liver Disease Questionnaire (CLDQ))
}

\begin{abstract}
Objectives The Chronic Liver Disease Questionnaire (CLDQ) is a validated tool measuring Health Related Quality of Life among patients with cirrhosis. The aim of this study was to validate a Sinhala version of the CLDQ (SCLDQ) and to test its correlation with the degree of liver dysfunction in a cohort of Sri Lankan patients with cirrhosis.

Methods A standard translation method was used. Pilot testing was done with relevant cultural and language adaptations. The final version and the WHO Quality of Life-BREF (WHOQOL-BREF) validated Sinhala version were administered to patients with chronic lever disease (CLD). SCLDQ was re-administered 4 weeks later to test internal consistency and reliability. The validaty and reliability were assessed by Cronabach's alpha, intraclass correlation coefficient (ICC) and Pearson's correlation coefficient. ANOVA and Pearson's correlation were used to assess correlation with the degree of liver dysfunction.
\end{abstract}

Results Validation was done with 214 participants [mean age 55.6 years (SD 10.4) male 77.6\%]. Cronabach's alpha was 0.926 . Intra-class correlations varied from
0.431 to 0.912 and all were significant $(p<0.001)$. Retesting was done on a sub-sample of 18 participants. Test-retest correlation was $0.695(p=0.008)$. WHO-BREF was administered to a sub-sample of 48 subjects. There was a significant correlation (Pearson's $r=0.391$; $p=0.004$ ) between SCLDQ and WHOQOL BREF. SCLDQ was significantly associated with MELD $(r=-0.13$; $p=0.038)$, MELD sodium $(r=-0.223 ; p=0.002)$, serum bilirubin ( $r=-0.124 ; p=0.036)$, serum sodium $(r=0.172$; $p=0.009)$, serum albumin $(r=0.201 ; p=0.003)$ and Child grade $(\mathrm{f}=3.687 ; p=0.027)$.

Conclusions CLDQ is a reliable and valid tool to assess quality of life of Sri Lankan patients with cirrhosis and correlates well with known indices of disease severity.

Ceylon Medical Journal 2013; 58: 156-62

\section{Introduction}

Health related quality of life (HRQL) is important in people with chronic diseases. Cirrhosis of the liver has a considerable effect on patients' physical and psychosocial wellbeing. The progression of symptoms, functional

${ }^{1}$ University Medical Unit, Colombo North Teaching Hospital, and Departments of ${ }^{2}$ Medicine, ${ }^{3}$ Pharmacology and ${ }^{4}$ Public Health, Faculty of Medicine, University of Kelaniya, Ragama, Sri Lanka.

Correspondence: JKNDM, e-mail: <jkndmiththinda@gmail.com>. Received 4 June 2013 and revised version accepted 9 October 2013. Competing interests: none declared. 